\title{
A Pressurized Tank for High Flow Rate Atomization Studies
}

\author{
Thomas J. Burtnett ${ }^{\star 1}$, Timothy B. Morgan ${ }^{1}$, Timothy C. Dahlstrom ${ }^{1}$, Alberto Aliseda ${ }^{2}$, and \\ Theodore J. Heindel ${ }^{1}$ \\ ${ }^{1}$ Center for Multiphase Flow Research and Education and Department of Mechanical \\ Engineering, lowa State University, Ames, IA 20011-2161 \\ ${ }^{2}$ Department of Mechanical Engineering, University of Washington, Seattle, WA 98195-2600 \\ USA \\ *tjb4cy@gmail.com
}

\begin{abstract}
Atomization is useful in many applications including combustion, spray painting, and fire suppression. To form a more complete understanding of the atomization process, it is necessary to study the near-, mid-, and far-field regions of a spray. Previous studies from this group, as well as from collaborators, have explored the near- and mid-field regions of a canonical airblast atomizer under atmospheric conditions. To provide a more complete atomization assessment, experimental spray measurements in pressurized environments are necessary. The Chamber for Assorted Pressurized Spray sUrveiLlancE, or CAPSULE, has been designed and constructed to operate the canonical airblast atomizer at pressures up to $1 \mathrm{MPa}$ and volumetric gas flow rates of nearly 4000 SLPM. The CAPSULE is a $190 \mathrm{~L}$ (50 gallon), 316L stainless steel pressure vessel equipped with six sight glasses to collect atomization data using multiple experimental techniques, including backlit imaging, Phase Doppler Particle Analysis (PDPA), and high-intensity X-ray radiography. The CAPSULE is fed by compressed air lines for both co-axial and swirl flow conditions. This paper provides an overview of the CAPSULE design, the major components in the flow loop, and the canonical airblast atomizer. Preliminary backlit imaging results are presented for ambient pressures in the range 0.1-0.5 MPa.
\end{abstract}

\section{Keywords}

Airblast atomizer, backlit imaging, pressure vessel, system design

\section{Introduction}

Spray atomizers are used in a variety of industries from powder coating to fire suppression. Spray dynamics and investigation techniques differ by spray region under investigation. Generally, sprays are divided into the near-, mid-, and far-field regions which relate to the distance from the atomizer exit. Data collection and modelling of all three regions are necessary to form a complete understanding of the spray. The near-field region is made up of large fluid sheets, long ligaments, and droplets making it optically dense. To penetrate this region and collect meaningful data, techniques such as X-ray radiography have been used successfully [1,2]. Visual light techniques, such as Phase Doppler Particle Analysis and shadowgraphy, are useful in less dense regions where the spray has broken up into ligaments and finer droplets [3,4]. These techniques can also be used to acquire measurements of the liquid intact length and spray angle, characterizing the breakup behavior from atomizers [5].

Furthermore, the ambient conditions of sprays are often taken to elevated pressures, prominent in combustion applications. X-ray and visual light techniques have been successfully implemented at these conditions [6, 7]. However, investigations at elevated pressures have intrinsic design challenges. These studies require a pressure vessel with visual or X-ray access windows. Often these ports limit optical access to the spray due to the 
atomizer being inside the pressure vessel in a fixed position and can make it difficult to fully characterize the spray.

The Chamber for Assorted Pressurized Spray sUrveiLlancE, or CAPSULE, is a system designed for pressurized environments up to $1 \mathrm{MPa}$ (10 bar), investigations in the near- and mid-field, and for simultaneous visual and X-ray techniques. This paper will outline its design and how it is used to collect data in the near- and mid-field regions. It will also deliver preliminary near-field spray angle measurements taken at ambient and elevated pressures of up to $0.5 \mathrm{MPa}$ using backlit imaging at lowa State University.

\section{Material and Methods}

It is planned to use the CAPSULE at three different testing locations, two of which have a maximum sustained compressed air capability of $0.5 \mathrm{MPa}$ while the third can operate at $1 \mathrm{MPa}$. Thus, the CAPSULE was constructed for a $1 \mathrm{MPa}$ maximum operating pressure, with the initial operation and flow loop rating set at $0.5 \mathrm{MPa}$. Data collected with the CAPSULE will be compared to recent data collected under atmospheric conditions using the same canonical airblast atomizer design [8,9]. Under atmospheric conditions, the highest gas flow rate was 1270 SLPM. The equivalent condition at $0.5 \mathrm{MPa}$ and a constant momentum flux ratio is 2840 SLPM, which sets the required mass flow rate in the flow loop.

The CAPSULE is a custom $190 \mathrm{~L}$ (50 gallon) pressure vessel made from $316 \mathrm{~L}$ stainless steel by Alloy Products Corporation. It has an internal diameter of $49.53 \mathrm{~cm}$ (19.5 in). It has three primary sections that are bolted together with $50.8 \mathrm{~cm}$ (20 in ANSI) flanges (Figure 1). These components include the bottom visualization ring, the $30.5 \mathrm{~cm}$ (12 in) extension ring, and the top lid. Each component is designed and built in accordance with ASME Section VIII Div. 1 and the chamber is pressure-rated up to $1.72 \mathrm{MPa}$ (250 PSI) at $37.8^{\circ} \mathrm{C}\left(100^{\circ} \mathrm{F}\right)$. When fully assembled, the CAPSULE itself weighs approximately $825 \mathrm{~kg}$ $(1820 \mathrm{lb})$ and stands approximately $1.4 \mathrm{~m}$ (55 in) tall. The extension ring is required for midfield testing and is removed for any near-field experimentation, which is the focus of the preliminary data presented in this paper. The CAPSULE and its flow loop can handle various gas/liquid flows, but this paper will focus on its use with air/water sprays.

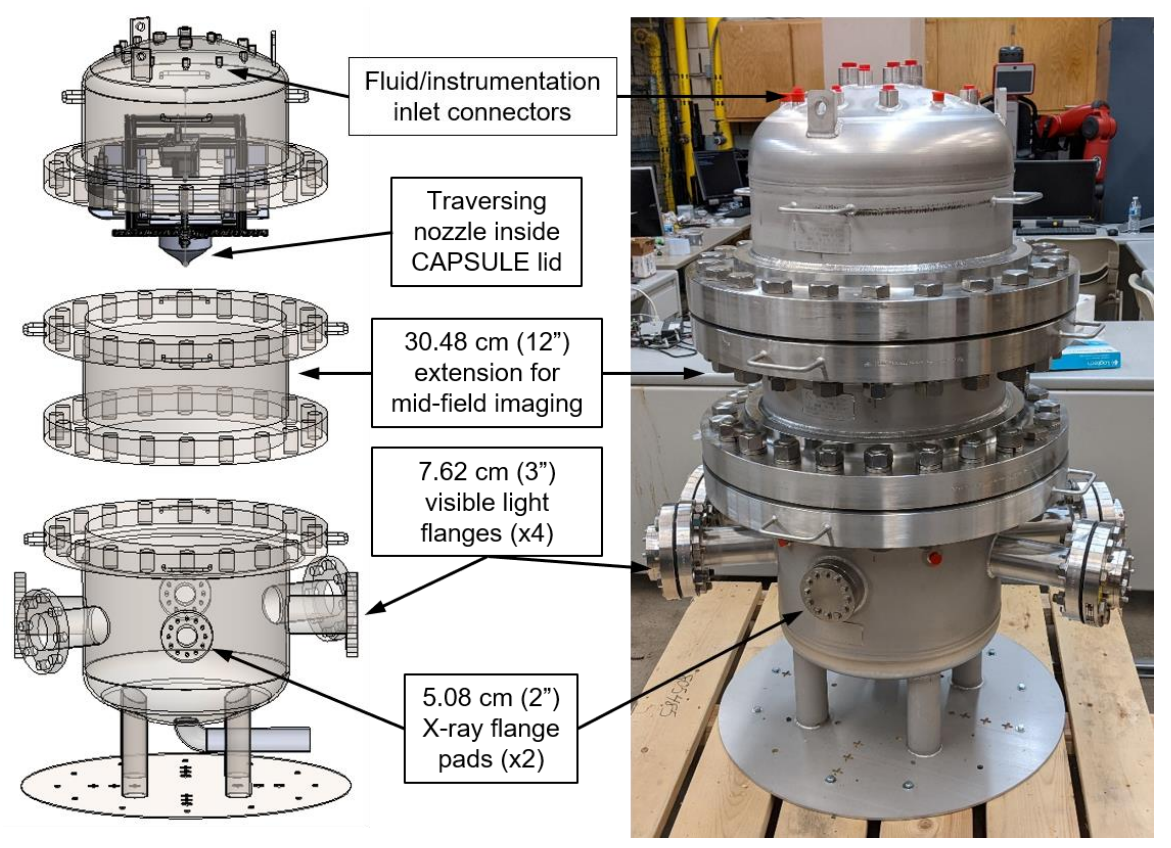

Figure 1. Key features of the CAPSULE. Adapted from [11]. 
The bottom visualization ring has six sight glasses (three pairs). Four are connected to $7.62 \mathrm{~cm}$ (3 in) ANSI Class 300 flanges that are extended away from the CAPSULE outer surface by lengths of pipe. The sight glasses are made of borosilicate glass. The two pairs are situated $30^{\circ}$ apart (Figure 2) for future PDPA measurements and other visual light experiments. Two custom $5.08 \mathrm{~cm}$ (2 in) flange pads are welded directly to the side of the CAPSULE at the $90^{\circ}$ and $270^{\circ}$ positions. These pads are designed for X-ray investigations at the

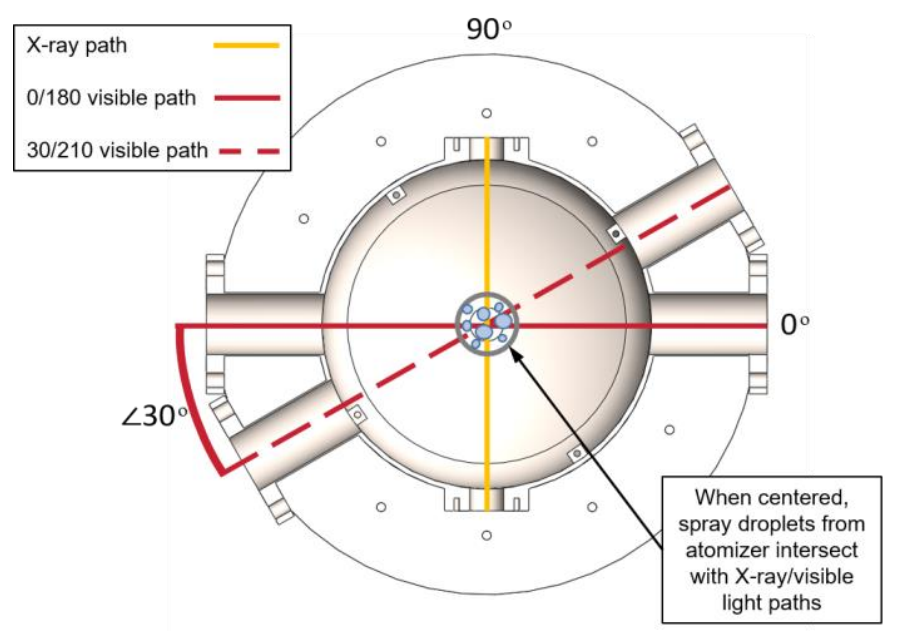

Figure 2. Positioning of the sight glass channels. Adapted from [11].

Advanced Photon Source (APS) where there are matching polyimide film (Kapton) window sight glasses. During visible light experimentation, the $\mathrm{X}$-ray ports are capped with a blind flange. The pads for the X-ray flanges were welded directly to the vessel to minimize the X-ray attenuation in the pressurized air. Above each of the sight glass ports on the interior of the vessel are mounts for $7.62 \mathrm{~cm}$ (3 in) long Exair Super Air Knives. These knives emit a thin sheet of air to prevent water droplets from accumulating on the sight glasses. The air knives are fed in matching pairs based on the visual path from entry ports on the vessel walls. A stainless-steel mesh has also been bolted near the bottom of the vessel to prevent water rebound off the bottom of the CASPULE. The CAPSULE bottom section has been painted with Rustoleum High Performance Flat Black paint to reduce reflections created during visual light experiments. Exhaust air and water leave the bottom through a $5.08 \mathrm{~cm}(2 \mathrm{in})$ elbowed pipe and connect to the rest of the exhaust system.

The lid of the vessel houses the CAPSULE gas/fluid liquid inlets and instrumentation ports. Two $2.54 \mathrm{~cm}$ (1 in NPT) ports are used for co-axial and swirl gas inlets and a $1.27 \mathrm{~cm}$ (1/2 in NPT) port is used for the water inlet. The other ports are for a dial pressure gauge, a $0.86 \mathrm{MPa}$ (125 PSI) safety valve, a temperature probe, two electrical pass-throughs, a valve for manually depressurizing the tank, and a pressure transducer. There are four pressure transducers throughout the system. Each have a measurement range of $0-2.0 \mathrm{MPa}(0-300$ PSI; PX359-300AI from Omega Engineering), report out on a 4-20 mA scale, and have accuracies of $+/-0.25 \%$. The lid also houses brackets for internally mounting the airblast atomizer and positioning stages.

The flow loop consists of three lines (co-axial air, swirl air, and water) and an exhaust segment (Figure 3). The co-axial air and swirl air lines are identical in almost all aspects. Compressed source air is first passed through a $5 \mu \mathrm{m}$ filter to remove contaminants, and then regulated down to operating pressure using manual pressure regulators. A Burkert Type 3361 electronic proportioning valve is used on both the co-axial and swirl air lines to moderate the flow rates. Due to the CAPSULE's planned X-ray work, remote control is necessary and is achieved by connecting the valves to PID controllers and toggle switches that force the valves full-open, under computer-control, or full-close. Both the co-axial and swirl lines have three differential flow meters from Omega Engineering. The co-axial line has a 250 SLPM, 1500 SLPM, and 3000 SLPM meter (model numbers FMA-1611A-I, FMA-1621A-I, and FMA-1623A-I, respectively). The swirl airline's only difference is instead of 1500 SLPM there 
is a 1000 SLPM meter in use (FMA-1613A-I). Differential pressure flow meters were chosen for their fast response time $(<10 \mathrm{~ms})$ and low error in measured flow $\pm(0.8 \%$ of reading $+0.2 \%$ full scale). Only one meter for each line is used at a time to minimize the error at low flow rates, and each flow meter can be closed off by two ball valves. The air lines then pass pressure transducers and enter the CAPSULE before being split into four $1.27 \mathrm{~cm} \mathrm{(1/2} \mathrm{in)}$ hose lines by a custom air manifold to be distributed to the atomizer.

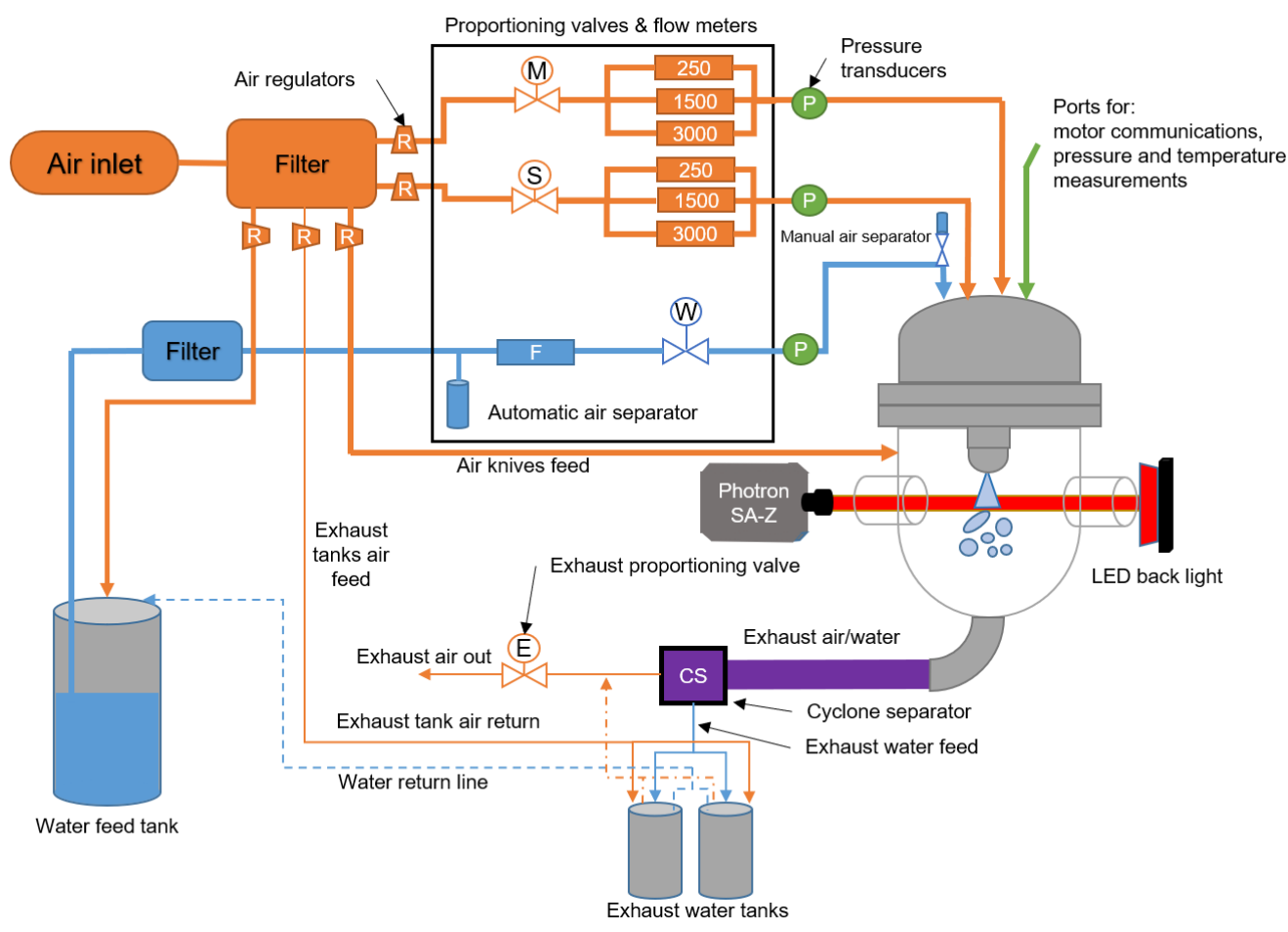

Figure 3. Flow loop layout of the CAPSULE system in back-illuminated operation

The water line uses a $113.6 \mathrm{~L}$ (30 gallon) stainless steel feed tank, that when pressurized, sends distilled water through a $20 \mu \mathrm{m}$ filter. If air bubbles are part of the water flow, they are removed via an air separator before the water passes through an Atrato ultrasonic flow meter (720-V-2-0-SD) that has a measurement range of $0.01-1.7 \mathrm{~L} / \mathrm{min}$ and an accuracy of $\pm 1 \%$. A Hass ECV-250-316SS-4X proportioning valve is used to control the water flow rate before it passes by a pressure transducer. Finally, the water passes through a tee with the downwards end leading into the vessel and the upwards end having a long section of tube with a ball valve on the end for initially purging air from the water line.

The air-water spray and any contributing air (e.g., the air knives) exit the CAPSULE through the exhaust pipe into a TLV DC7 cyclone separator that removes water from the air. Any separated water is expelled into two identical $37.9 \mathrm{~L}$ (10 gallon) stainless steel tanks. As these tanks fill, the air inside them is returned to the outgoing exhaust air (Figure 3). There is an identical Burkert Type 3361 proportioning valve on the air exit line that controls the air volume exiting the system to regulate the pressure inside the CAPSULE. Captured water is returned to the feed tank by closing off the exhaust tanks from the cyclone separator and air exit line, and opening valves that return the water to the feed tank.

The airblast canonical atomizer is based off previous studies using a similar nozzle [10]. The atomizer is composed of four parts: a water needle, a water nut, a plenum, and the air nozzle. The 6061 aluminum water needle has a nominal $d_{l}=2 \mathrm{~mm}(0.079 \mathrm{in})$ ID hole reamed through its center. The outer diameter is $D_{l}=3 \mathrm{~mm}(0.12 \mathrm{in})$, and the entire length of 
the needle is $110 \mathrm{~mm}$ (4.33 in). The exterior contour of the needle was pre-established in [10]. The top of the needle slides through a hole in the plenum (Figure 4a) and threads into the water nut. The water nut is made from stock hexagonal 6061 aluminum and simply acts to secure and align the water needle. Contact surfaces on the atomizer use a fluoroelastomer (Viton) O-ring to ensure a thorough seal.

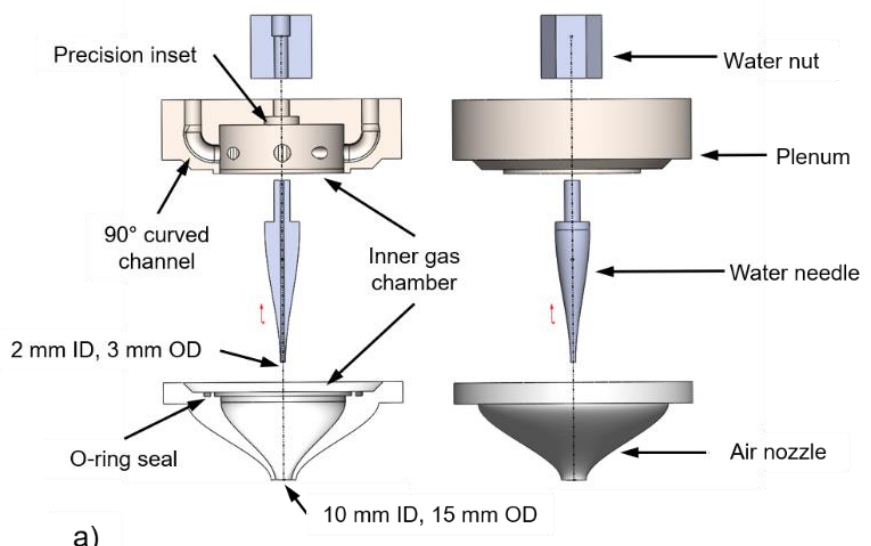

a)

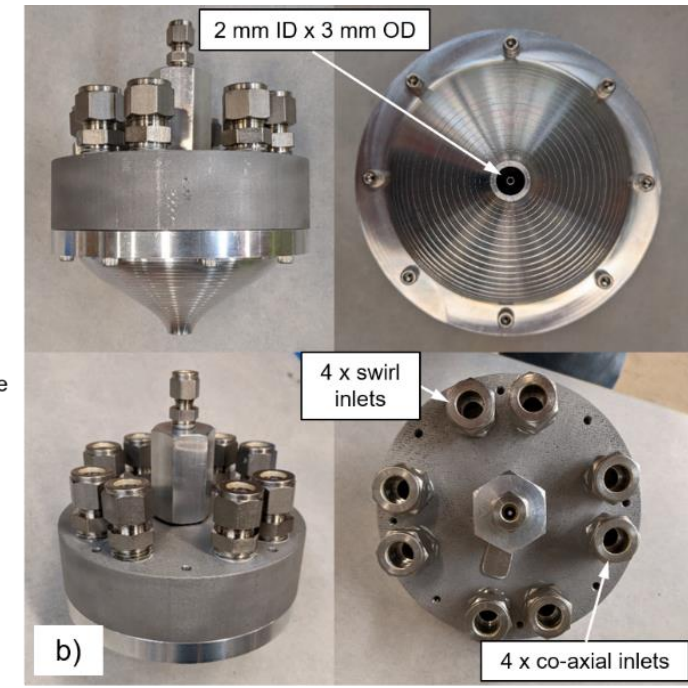

Figure 4. a) Exploded CAD view of the spray atomizer and b) assembled atomizer. Adapted from [11].

Surrounding the liquid needle are a gas plenum and nozzle. Four $1.27 \mathrm{~cm}(1 / 2 \mathrm{in}) \mathrm{co}-$ axial and four $0.9525 \mathrm{~cm}$ (3/8 in) swirl inlet channels enter the top (Figure 4b) and curve $90^{\circ}$ so that the co-axial air flow enters perpendicular to the water flow and the swirl air enters tangentially. To provide the appropriate air channeling, the plenum was 3D-printed from an aluminum alloy (AISi10Mg). The inner chamber geometry matches that of previous atomizers except for the exit shape of the inlets into the chamber. To 3D-print the metal without drooping, the circular exit was changed to a "teardrop" shape. The bottom geometry of the chamber has a $45^{\circ}$ chamfer and a precision ring to align the air nozzle, and the interior surface has been post-machined to reduce surface roughness. The air nozzle was machined out of 6061 aluminum. Its inner contour matches the previous nozzle iterations [10]. The exit of the nozzle has an inner diameter $d_{g}=10 \mathrm{~mm}$ (0.39 in) and an outer diameter of $D_{g}=15 \mathrm{~mm}(0.59 \mathrm{in})$. The nozzle is bolted to the plenum so it may be switched for other material or exit geometries in future experiments.

Inside the CAPSULE, the atomizer has a full horizontal and vertical motion range of $20.32 \mathrm{~cm}$ (8 in) and $12.7 \mathrm{~cm}$ (5 in), respectively, providing a range of positions for near- and mid-field investigations. Note the near-field investigations are performed without the extension ring while the mid-field investigations utilize the extension ring. Vertical motion is controlled by a Velmex BiSlide stage and four linear motion bearings opposite of the stage to prevent cantilevering (Figure 5a). The horizontal motion is handled by an Velmex XSlide motion stage with two linear bearings on a single shaft (Figure $5 \mathbf{b}$ ). Both stages are equipped with a lead screw with an accuracy of $38.1 \mu \mathrm{m}$ per $25.4 \mathrm{~cm}$ (0.0015 in per $10 \mathrm{in})$ and a drive motor with a step angle of $1.8^{\circ}$. The stages operate at $5 \mu \mathrm{m}$ per step. The assembly is held together on an extruded aluminum frame that slides into the top of the CAPSULE and bolts into eight welded brackets in the lid. Outside of the CAPSULE, a Velmex VM-2 motion controller passes the serial communications between the motors in the vessel and a LabView program monitoring the current stage locations. 
The system is operated by an in-house LabView program with an eight module DAQ chassis. A PID controller is implemented to control the water flow rate, co-axial flow rate, swirl flow rate, and CAPSULE pressure. The LabView program also controls nozzle motion within the CAPSULE, allows for flow meter selection, provides sensor and actuator error monitoring, and external measurement device synchronization, amongst other functions. For more details regarding this system, see [11].

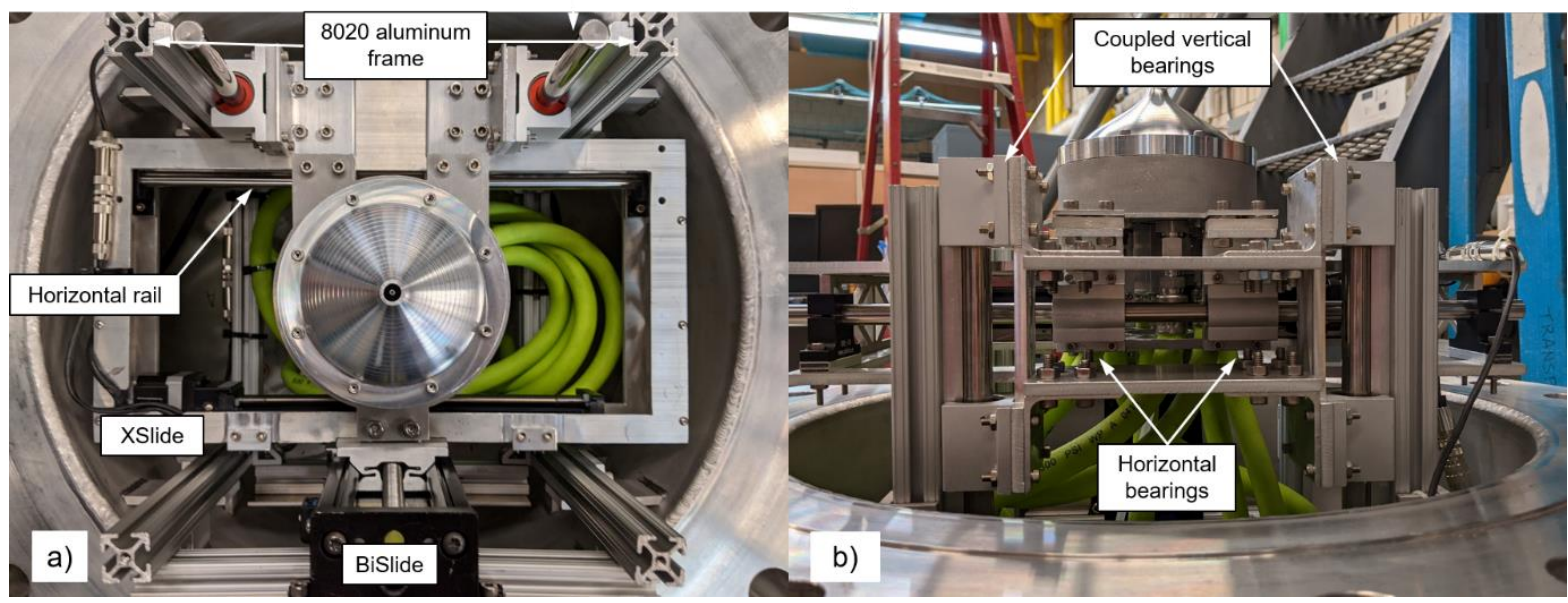

Figure 5. a) Top-down image of nozzle mounted in CAPSULE and b) side image of nozzle mounted in CAPSULE (note the CAPSULE top and mounted nozzle are oriented upside-down before final CAPSULE assembly).

The spray parameters important to this study include the gas and liquid Reynolds numbers $\left(R e_{g}\right.$ and $\left.R e_{l}\right)$, swirl ratio $(S R)$, and the momentum flux ratio $(M)$ :

$$
\begin{aligned}
& R e_{I}=U_{I} d_{l} / v_{l} \\
& R e_{g}=U_{g} d_{e f f} / v_{g} \\
& S R=Q_{s} / Q_{g} \\
& M=\rho_{g} U_{g}{ }^{2} / \rho_{l} U_{l}^{2}
\end{aligned}
$$

Preliminary backlit test conditions used a MicroBrite BT200100-625IC LED screen with a Photron SA-Z high-speed camera. The camera was equipped with, in order, a $36 \mathrm{~mm}$ lens extension, a Nikon 1.4x teleconverter, and a Nikon $180 \mathrm{~mm}$ lens. Spray results were sampled at a rate of 1000 FPS with a shutter speed of $1 / 80000 \mathrm{sec}$. The CAPSULE sight glasses not in use were covered with a heavy black cloth to block out ambient light.

Preliminary test conditions were determined by holding the momentum flux ratio constant at $M=27$ and increasing the pressure for the case of $R e_{l}=1100$. Because of the compressibility effects of air, the gas Reynolds number increased from $R e_{g}=36,000$ at 0.1 $\mathrm{MPa}$ to $R e_{g}=80,700$ at $0.5 \mathrm{MPa}$. For each total gas flow condition, a range of $S R$ was imaged. The raw images were normalized against an average "flat field" image with no spray. Postprocessing was completed to find the spray angle using the method in [12].

\section{Results and Discussion}

An instantaneous image taken at $0.5 \mathrm{MPa}$ is shown in Figure 6a. The image includes the atomizer tip and the field of view extends approximately $30 \mathrm{~mm}$ downstream. Multiple (1000) images were averaged per test and the resulting image after post-processing allows 
for the spray angle to be automatically measured. The spray angle, $\theta$, is defined as the average angle between the outer edge of the spray and the spray centerline (Figure 6b). Conditions were repeated five times in a randomized order for each pressure$S R$ combination and the average spray angle is reported.

The average spray angle as a function of swirl ratio for 5 different ambient pressures is shown in Figure

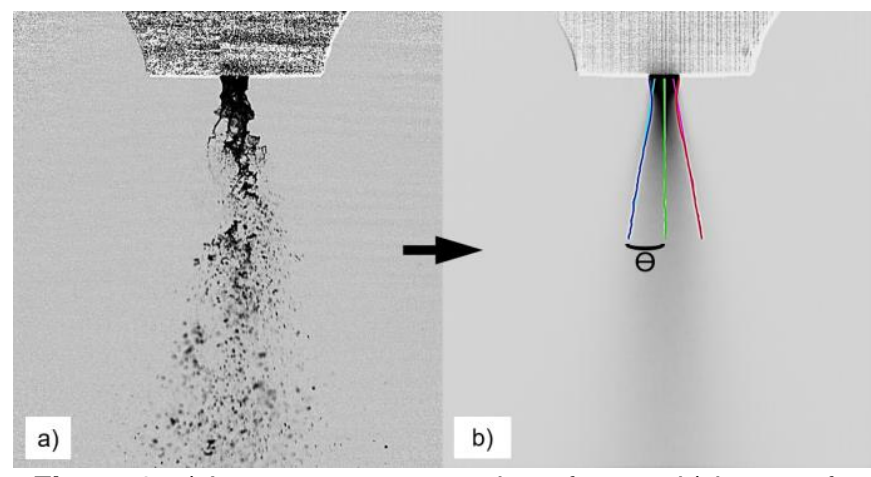

Figure 6. a) Instantaneous snapshot of spray, b) image of a spray after averaging, showing spray angle.

7. The error bars represent \pm one standard deviation of the five tests at each condition. The error, generally, is greatest at when the $S R=1$, where the spray is more sporadic, and the spray angle is the widest. As the $S R$ increases for all conditions, the average spray angle generally increases, with the largest increase between $S R=0.25$ and $S R=0.5$. Investigations beyond $S R=1$ are necessary to determine if this trend continues.

Changing the ambient pressure from 0.1 to $0.5 \mathrm{MPa}$ made little difference in the spray angle at lower swirl ratios $(S R=0$ to 0.25$)$. At these $S R$, the spray angle remains constant at $\sim 10-11^{\circ}$ with the increasing pressure. At a $S R \geq 0.75$, increasing ambient pressure begins to influence the spray angle, where spray angle increases with pressure. More research is necessary to confirm this trend at different momentum flux ratios and liquid volumetric flow rates.

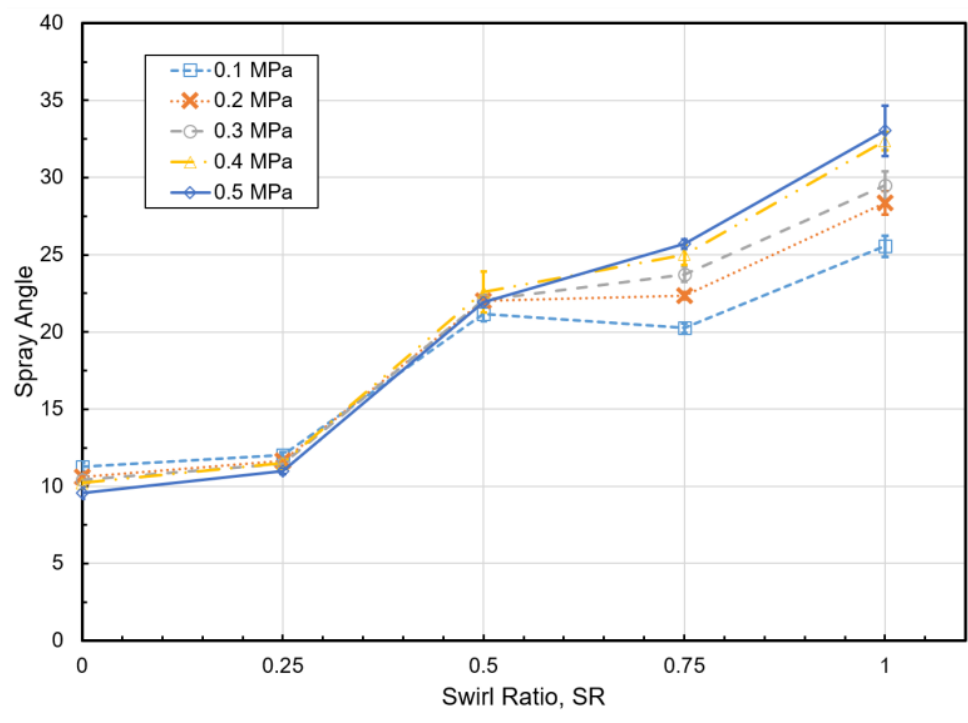

Figure 7. Spray angles at increasing SR and pressures for $M=27$

\section{Conclusions}

A pressure vessel, flow loop, and atomizer have been successfully designed, constructed, and tested. The CAPSULE is capable of incorporating multiple data acquisition techniques to characterize large regions of the spray. Preliminary back-illuminated spray angle measurements were completed, during which the CAPSULE was operated up to $0.5 \mathrm{MPa}$ (5bar). The preliminary spray angle results show an increase in spray angle with increasing swirl ratio. Also, as the ambient pressure increases, spray angle increases at higher swirl ratios $(\geq 0.75)$ but remains independent of pressure at lower swirl ratios. Further exploration of flow rates, pressures, and spray positions are planned in future research.

\section{Acknowledgments}

This work was sponsored by the Office of Naval Research (ONR) as part of the Multidisciplinary University Research Initiatives (MURI) Program, under grant number 
N000141612617. The camera used in this research was purchased through an ONR Defense University Research Instrumentation Program (DURIP) grant number N000141812380. The views and conclusions contained herein are those of the authors only and should not be interpreted as representing those of ONR, the U.S. Navy or the U.S. Government.

\section{Nomenclature}

$d_{\text {eff }} \quad$ nozzle effective diameter $[\mathrm{mm}], d_{\text {eff }}=\left(d_{g}^{2}-D_{l}^{2}\right)^{0.5}$

$d_{g} \quad$ gas nozzle inner diameter [mm]

$d_{l} \quad$ liquid needle inner diameter [mm]

$D_{g} \quad$ gas nozzle outer diameter [mm]

$D_{l} \quad$ liquid needle outer diameter [mm]

$M \quad$ momentum flux ratio

$Q_{g} \quad$ co-axial volumetric flow rate [LPM]

$Q_{s} \quad$ swirl volumetric flow rate [LPM]

$R e_{\text {I }} \quad$ liquid Reynolds number

$R e_{g} \quad$ gas Reynolds number

SR swirl ratio

$U_{g} \quad$ mean gas velocity $[\mathrm{m} / \mathrm{s}]$

$U_{l} \quad$ mean liquid velocity $[\mathrm{m} / \mathrm{s}]$

$v_{1} \quad$ liquid dynamic viscosity[ $\left[\mathrm{N}^{*} \mathrm{~s} / \mathrm{m}^{2}\right]$

$v_{g} \quad$ gas dynamic viscosity $\left[\mathrm{N}^{*} \mathrm{~s} / \mathrm{m}^{2}\right]$

$\rho_{g} \quad$ gas density $\left[\mathrm{kg} / \mathrm{m}^{3}\right]$

$\rho_{\mathrm{l}} \quad$ gas density $\left[\mathrm{kg} / \mathrm{m}^{3}\right]$

$\theta \quad$ spray angle

\section{References}

[1] Heindel, T.J., 2018, Atomization and Sprays, 28(11), pp. 1029-1059.

[2] Lightfoot, M.D.A., Schumaker, S.A., Dancyzyk, S.A., Kastengren, A.L., May 17.-20. 2015, $27^{\text {th }}$ Annual Conference on Liquid Atomization and Spray Systems.

[3] Aliseda, A., Hopfinger, E.J., Lasheras, J.C., Kremer, D.M., Berchielli, A., Connolly E.K., 2008, International Journal of Multiphase Flow, 34(2), pp. 161-175.

[4] Charalampous, G., Hadjiyiannis, C., Hardalupas, Y., 2016, Measurement, 89, pp. 288-299.

[5] Fu, Q., and Yang, L., 2015, Aerospace Science and Technology, 47, pp 154-163.

[6] Kastengren, A.L., Powel, C.F., Wang, Y., Im, K., Wang, J., 2009, Atomization and Sprays, 19(11), pp. 1031-1044.

[7] Leong, M.Y, McDonell, V.G., Samuelsen, G. S., 2001, Journal of Propulsion and Power, 17(5), pp. 1076-1084.

[8] Bothell, J.K., Machicoane, N., Li, D., Morgan, T.B., Aliseda, A., Kastengren, A.L., Heindel, T.J., 2020, International Journal of Multiphase Flow, 125.

[9] Machicoane, N., Ricard, G., Osuna-Orozco, R., Huck, P., Aliseda, A., 2020, International Journal of Multiphase Flow, 129.

[10] Machicoane, N. and Aliseda, A., May 15.-18. 2017, 29th Annual Conference on Liquid Atomization and Spray Systems.

[11] Burtnett, T.J., 2021, "A movable experimental system for observing pressurized sprays," M.S. Thesis, lowa State University, Ames, IA.

[12] Morgan, T.B., and Heindel, T.J., May 16.-19. 2021, 31st Annual Conference on Liquid Atomization and Spray Systems, (To Appear). 